\title{
Estimation of the industrial building reinforced concrete beams' residual life under corrosive media influence
}

\author{
Boris Gritsenko, Valeria Pshenichkina, Anton Glukhov*, and Natalia Sidorova \\ Volgograd State Technical University, 400001, Volgograd, Russia
}

\begin{abstract}
The dominant factor determining chemical industry objects' durability is the corrosive wear of the stretched reinforcement and the compressed zone of concrete. The article presents a methodology and results of a numerical assessment of the residual life of the reinforced concrete frame beams of an industrial building operating in an aggressive environment. According to the full-scale engineering survey results, the most damaged frame structures - the beams of the intermediate floors were identified. The period of concrete protective layer complete neutralization, the degree of corrosion damage to the working reinforcement, the compressed concrete neutralized layer depth, the change in its strength characteristics with depth and the degree of its heterogeneity were determined by the field measurements using the standard and non-standard methods of nondestructive testing. A linear law of the accumulation of corrosion damage to concrete in the compressed zone and the rate of corrosion damage in the working reinforcement after the concrete protective properties' exhaustion is adopted. A normative design apparatus is used for the first group of limiting states in relation to the most loaded section. For an adequate assessment and prediction of the residual resource, the main emphasis is on experimental and diagnostic methods.
\end{abstract}

\section{Features of the bent reinforced concrete elements work under corrosive attack}

Really exploited industrial structures are in extremely difficult operating conditions. On the one hand, there is a relatively high level of operational loads and a fairly frequent change of technological equipment, on the other hand, the presence of various aggressive media (gas, liquid, etc.). In addition, the technology of operating the supporting structures is often practically absent, i.e., in fact, there is a high level of corrosive effects with a practical absence of measures for anti-corrosion protection.

\footnotetext{
${ }^{*}$ Corresponding author: tracketbow@list.ru
} 
The numerous field examinations' results of the structures under these conditions showed that the dominant factor that reduces the structures' actual life is the corrosive wear of the stretched reinforcement and the concrete compressed zone.

At the same time, there are often no external signs of the limiting states onset, both of the I group of states and of the II (the formation of plastic hinges, cracks with an opening width of more than $0.1 \mathrm{~mm}$, significant deflections, etc.). However, at the same time, there is a significant corrosive wear of the longitudinal reinforcement cross-sectional area, damage to the concrete protective layer, changes in the deformation and strength characteristics of concrete, a decrease in the cross-sectional area of the concrete compressed zone. It should be noted the extreme heterogeneity of corrosion damage in various zones, even within a single structure, which is associated with the level and nature of these zones' stress-strain state, as well as with the intensity and nature of the local corrosion impact. That is, in real conditions, the stress-strain state is a factor that controls the concrete and reinforcement corrosive wear degradation processes rate and nature.

With the corrosive wear of concrete and reinforcement, a redistribution of the stress-strain state occurs (SSS) separate the zones within the structure against the background of a constant increase in its relative level. In this case, the onset of the limiting state of groups I and II is possible when a certain level of concrete and tensile reinforcement SSS compressed zone is reached, while maintaining the possibility of their joint work.

For statically indeterminate structural systems, the situation is further complicated by the fact that there is also a redistribution of efforts between the individual structures and groups with the corrosive wear accumulation.

The course nature and corrosion rate can be influenced by many factors: the physical and chemical parameters of the environment, the magnitude and nature of the structures' stressstrain state and the features of their operation. Mathematical modeling of the process of reinforced concrete structures' corrosion destruction is a very difficult problem, which remains completely unsolved at present.

The theoretical foundations for modeling the structures' interaction processes with the environment, calculating their durability are laid down in [1], the design of the reinforced concrete engineering structures' durability, taking into account degradation processes in concrete and reinforcement under the action of various aggressive media in a deterministic and probabilistic setting, is considered in [2]. Currently, a large number of studies are devoted to the experimental study of the processes of corrosion in concrete and reinforcement [3-7], as well as the measurement of the corrosion rate directly in real time [8,9]. Methods of probabilistic modeling of concrete and reinforcement wear and destruction during the propagation of corrosion and calculation of the reinforced concrete structures' reliability are considered in [10-13].

This paper presents a methodology for assessing the resource of bending reinforced concrete structures based on the results of their experimental and diagnostic studies and the use of engineering models adopted in the current regulatory documents.

\section{Characteristics of an operating industrial building and operating conditions of load-bearing structures}

The surveyed structure is a three-storey open independent stack-frame of dimensions in terms of $30 \times 15 \mathrm{~m}$ and a height of $25 \mathrm{~m}$. The operating time of the structure is 30 years. General view and structural diagram of the structure are shown in Fig. 1. 
The structure is designed as a building with a full frame, the first two floors are made of prefabricated reinforced concrete, the third floor is made of metal.

Technological equipment is located on the overlap of the first and second floors, the operating load from which is $15 \mathrm{kN} / \mathrm{m}^{2}$. The main load-bearing structures are exposed to the direct influence of the external environment (temperature, humidity, etc.). Individual zones are subject to regular soaking, freezing and thawing.
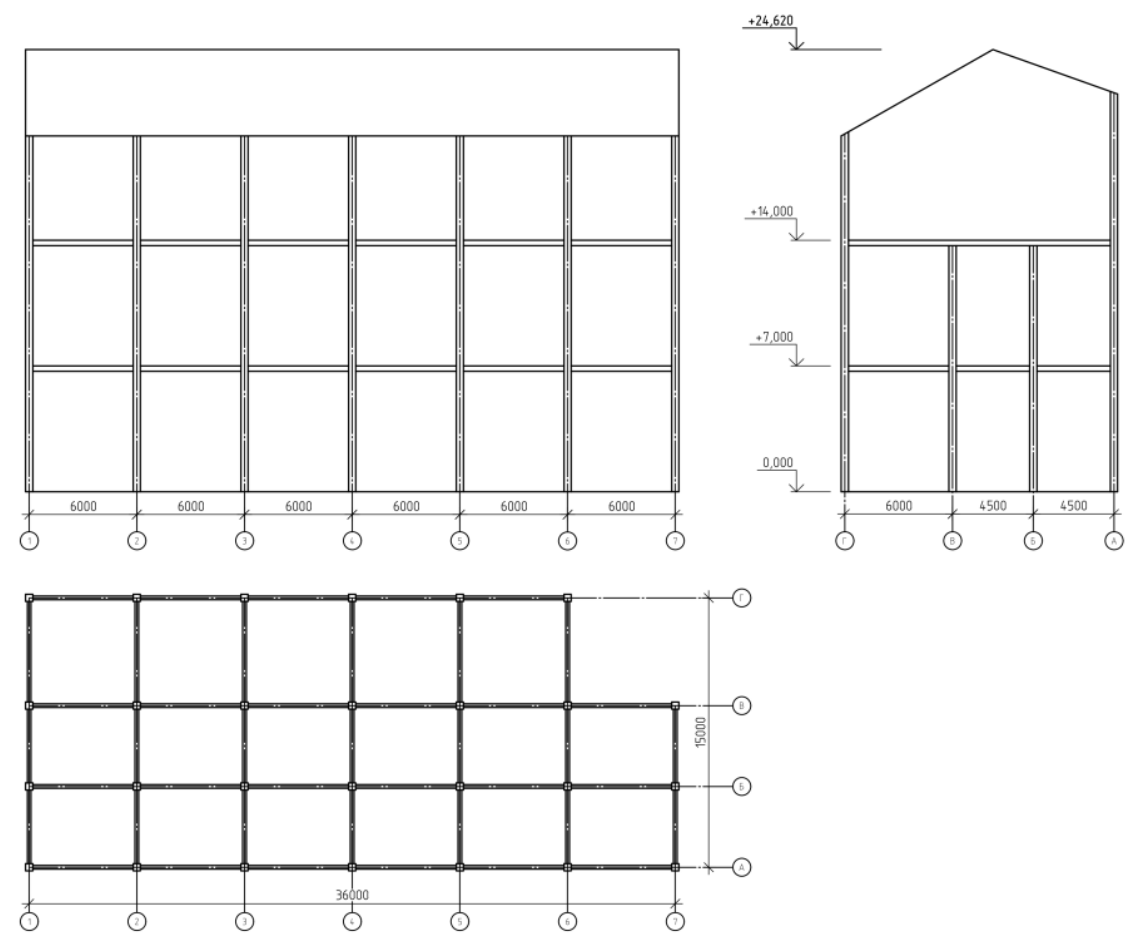

Fig. 1. General construction scheme

The technological process involves the use of recycled water, part of which is regularly spilled onto the supporting structures of the floor. The composition of circulating water includes, according to the laboratory, the following components that are aggressive towards reinforcement and concrete: $\mathrm{pH}-7,5$; $\mathrm{COD}-80,8 \mathrm{mg} / \mathrm{l}$; hydrogen sulfide $-0,34 \mathrm{mg} / \mathrm{l}$; alkalinity $-2,2$; petroleum products $-51,4 \mathrm{mg} / \mathrm{l}$; dry residue $-33,8 \mathrm{mg} / \mathrm{l}$; calcium hardness 2,6 mg/l; overall hardness - 3,6 mg/l; chlorides - 43,6 mg/l; mechanical impurities - 22,5 $\mathrm{mg} / \mathrm{l}$; iron $-0,66 \mathrm{mg} / \mathrm{l}$.

\section{Results of full-scale engineering survey of reinforced concrete beams of intermediate floors}

During the engineering survey, the study and registration of the beams' state characteristic external signs (the presence of damaged zones, cracks, etc.) was carried out; determination of the concrete wear, reinforcement, strength characteristics of concrete and the degree of its heterogeneity; the presence, location and orientation of cracks in the selected zones were recorded. 
Based on the results of a full-scale engineering survey, it was established:

- The greatest damage (III-IV category of the technical condition assessment [14]) was found in reinforced concrete beams located at 7.00, i.e., in the overlap of the 1 st floor: $33 \%$ for the beams B-4 and 10\% for the beams B-18 (Fig. 2). This is primarily due to the circulating water technological spills' intensity.

- The greatest corrosion damage to concrete and reinforcement takes place in the zones of the highest tensile stresses in concrete, which is associated with the presence of the concrete structure significant loosening and, as a consequence, intensive capillary inflow of an aggressive medium (chlorides) into the reinforcement area.

- Corrosion damage to concrete is mainly superficial to a depth of $40-50 \mathrm{~mm}$ in discharged zones and up to $20 \mathrm{~mm}$ of disposable surfaces. Moreover, in the zones of regular technological spills of technological water, the compressed zone concrete has an increased porosity to a depth of $40-50 \mathrm{~mm}$, up to $9 \%$, at $7.0 \%$ (pores with a size greater than $10 \times 10-6$ were taken into account by microscopic examination of the selected samples' prepared surface). At the same time, the protective properties of concrete to a depth of $50 \mathrm{~mm}$ are sharply reduced.

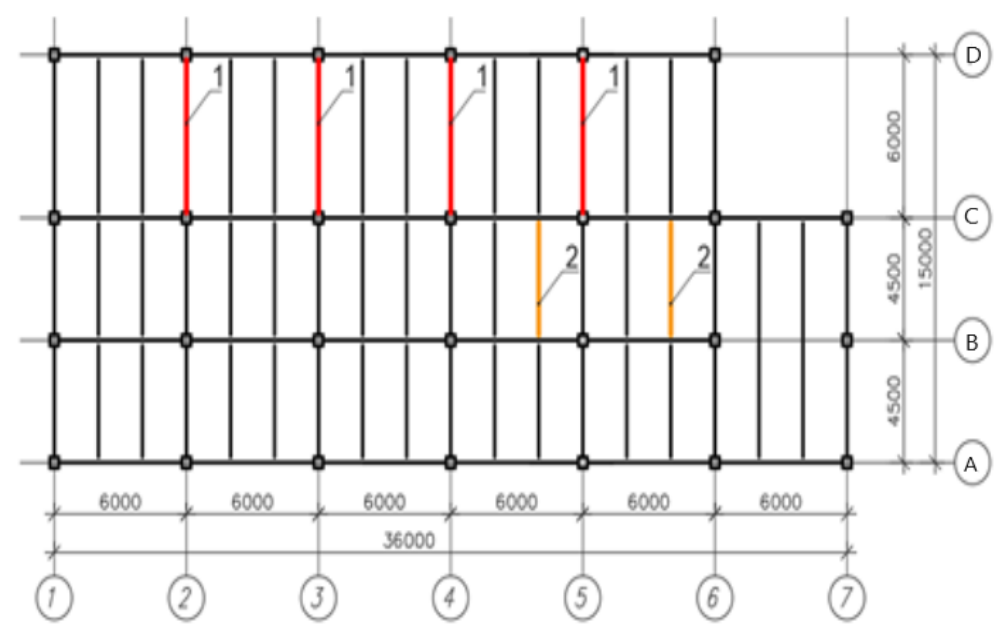

Fig. 2. Layout of the most damaged beams at the first-floor level, where 1 defines the beam B$4 ; 2$ defines the beam B-18

\section{Assessment of the bending elements' individual residual life}

The reinforced concrete beams' residual life of rectangular cross-section with double reinforcement is estimated under the following assumptions:

1. The integrity of the structure is preserved, i.e., corrosion processes do not affect the areas that provide the working reinforcement anchoring.

2. A normative calculation apparatus is used for the first group of limiting states in relation to the most loaded section.

3. A linear law of corrosion damage accumulation in the working reinforcement after the exhaustion of the concrete protective properties is adopted.

4. A linear law of the accumulation of corrosion damage to concrete is adopted after the end of the initial running-in stage, which corresponds to the concrete protective properties' exhaustion in relation to reinforcement. 
5. The fittings of the compressed zone are practically not exposed to corrosion.

At the time of the field survey, the following characteristics of the individual design are established.

1. Geometric dimensions.

2. The number, type and scheme of the most loaded sections reinforcement.

3. The volume of the damaged concrete cover and the reinforcement corrosive wear degree.

4. The depth of the compressed concrete neutralized layer and the change in strength characteristics with depth.

5. The actual design scheme of a reinforced concrete structure work and the stress-strain state nature.

6. Commencement of the facility commissioning and characteristics of corrosive environments.

The corrosion damage filling rate assessment to reinforcement is carried out as follows.

The period of complete neutralization of the concrete protective layer is determined experimentally by using several chemical indicators. Measurements are carried out in the zones of preserved concrete 1, 2, 3 near the neutral axis (Fig. 3).
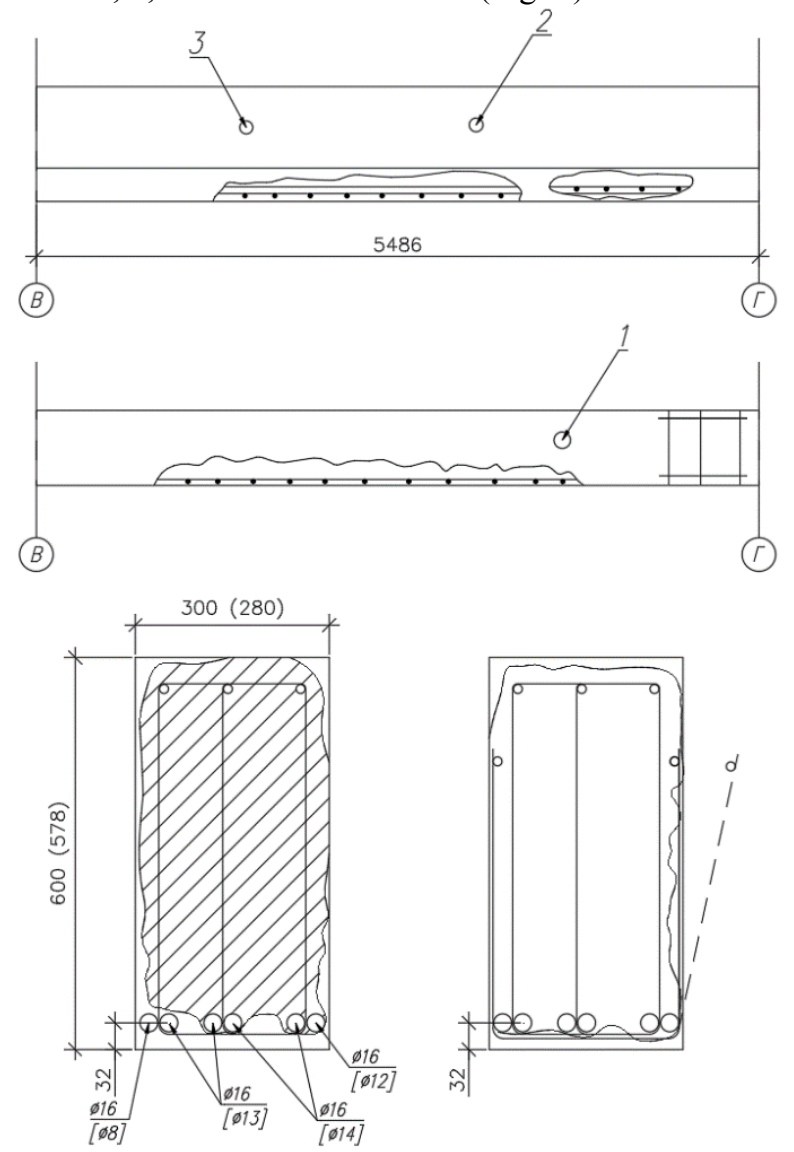

Fig. 3. Layout of damage in the beam B-4 along the axis 4/C-D. Longitudinal reinforcement does not correspond to the design; frames are offset to the side up to $60 \mathrm{~mm}$ 
We find time before the concrete protective functions exhaustion $\tau_{1}$

$$
\tau_{1}=\left(\frac{y_{1}}{y_{2}}\right)^{2} \cdot \tau_{2}
$$

where $y_{1}$ is concrete cover; $y_{2}$ is the depth of the neutral concrete layer at the time of the survey; $\tau_{2}$ denotes the time in years from the operation start to the examination moment.

The assessment of the stretched reinforcement corrosive wear rate was carried out by means of full-scale measurement of the area of the remaining reinforcement:

$$
V_{s}=\frac{A_{s}-A_{s}^{r e s}}{\left(\tau_{2}-\tau_{1}\right) A_{s}},
$$

where $A_{S}^{\text {res }}$ is the reinforcement residual area in the most loaded section.

Estimation of the concrete corrosive wear rate in a compressed zone:

$$
V_{b}=\frac{A_{b}-A_{b}^{r e s}}{\left(\tau_{2}-\tau_{1}\right) A_{b}}
$$

where $A_{b}^{\text {res }}$ is the residual concrete sectional area, taking into account the actually damaged concrete layer; $A_{b}$ is the initial concrete area;

Residual strength $R_{b}^{r e s}$ concrete is determined taking into account the data of nondestructive control methods (ultrasonic, mechanical), taking into account the data on the concrete samples' porosity (cement stone), taken from different depths in a zone close to neutral.

The establishment of the structure actual design scheme is carried out taking into account the acting loads analysis, the conditions for their transfer, the type of supported nodes, the existing cracking pattern analysis. If an external examination of the cracking picture is diagnosed with an insufficient reliability degree, non-destructive ultrasonic methods are used.

After establishing the design model, we find the maximum bending moment $M$ in the most dangerous section, taking into account the actual loads.

We estimate the residual life of the beams in the following order:

We calculate the relative height of the concrete compressed zone in the most loaded section, taking into account corrosive wear:

$$
\xi=\frac{\left(1-\tau \cdot V_{s}\right) R_{s n} \cdot A_{s}-R_{s c} \cdot A_{s}^{\prime}}{\left(1-\tau \cdot V_{b}\right) R_{b n} \cdot b \cdot h_{0}}
$$


where $\tau$ is the duration of operation of the structure after the concrete has exhausted its protective function; $R_{s n}$ denotes the standard values of reinforcement strength in section; $A_{s}$ is a cross-sectional area of reinforcement at the time of commencement of operation; $R_{b n}$ is the strength of concrete at the time of commencement of operation; $b, h_{0}$ are the initial geometric dimensions of the section; $V_{s}, V_{b}$ denote the decline rate in the characteristics of reinforcement and concrete during corrosive wear.

Ultimate bending moment perceived by the section taking into account corrosive wear:

$$
M_{v}=B\left(1-\tau V_{b}\right) R_{b} \cdot b \cdot h_{0}^{2}+R_{s c} A_{s}^{\prime}\left(h_{0}-a^{\prime}\right) .
$$

Bearing capacity margin is the difference between effective moment $M$ and the limiting moment perceived by the cross section:

$$
\Delta M=M_{v}-M
$$

Then, solving the system of two equations

$$
\left.\begin{array}{l}
M=\xi_{3}\left(1-0,5 \xi_{3}\right)\left(1-\tau_{3} V_{b}\right) R_{b n} \cdot b \cdot h_{0}^{2}+R_{s c} A_{s}^{\prime}\left(h_{0}-a^{\prime}\right) \\
\xi_{3}=\frac{\left(1-\tau_{3} \cdot V_{s}\right) R_{s n} \cdot A_{s}-R_{s c n} \cdot A_{s}^{\prime}}{\left(1-\tau_{3} \cdot V_{b}\right) R_{b n} \cdot b \cdot h_{0}}
\end{array}\right\},
$$

at $\Delta M=0 \quad \tau_{3}$ and residual design life $T$ are found, i.e., the time before the first group limiting state onset from the examination moment:

$$
T=\left(\tau_{3}-\tau_{2}\right)
$$

The beam B-4 (in axes 4/C-D) residual life estimation.

General layouts of defects and damages in type beams B-4 are shown in Fig. 3.

According to the field measurements, the concrete cover layer thickness is: $y_{1}=3.2 \mathrm{~cm}$ $\pm 0,3 \mathrm{~cm}$; depth of neutralized concrete layer $y_{2}=5.6 \mathrm{~cm} \pm 0.5 \mathrm{~cm}$. Time from the operation start to the examination moment is $\tau_{2}=30$ years.

By the formula (1), we calculate $\tau_{1}=9,8$ years. We accept $\tau_{1}=10$ years.

The total area of the reinforcement at the time of the start of operation is equal to $A_{s}=10.3 \mathrm{~cm}^{2}$, and the remaining total area of reinforcement at the time of the survey, obtained from the actual measurement data of the residual diameter of the reinforcement $A_{S}^{\text {res }}=8.2 \mathrm{~cm}^{2}$. Find the stretched reinforcement corrosive wear rate (2), which is on average for all rods $V_{s}=1.02 \%$ in a year. 
The concrete corrosive wear rate in the compressed zone in the cross section of the maximum moments (3) is: $V_{b}=0.33 \%$ in year. The area of the preserved concrete is determined taking into account changes in thickness up to $2 \mathrm{~cm}$ on each side: $A_{b}^{\text {ref }}=1680$ $\mathrm{cm}^{2}$.

The strength characteristics of the concrete in the compressed zone of the beam are determined in 4 sections and are $R_{b n}=11 \mathrm{MPa}$.

Figure 4 shows a graph of the change in the ultimate bending moment $M_{v}(\mathrm{kN} \cdot \mathrm{m})$ beams B-4 in time depending on the concrete corrosive wear degree in the compressed zone $V_{b \tau}, \%$ and stretched reinforcement $V_{s \tau}, \%$. At the examination time (point 1 on the graph), the damage to the reinforcement is $\sim 30 \%$, concrete $\sim 6-10 \%$.

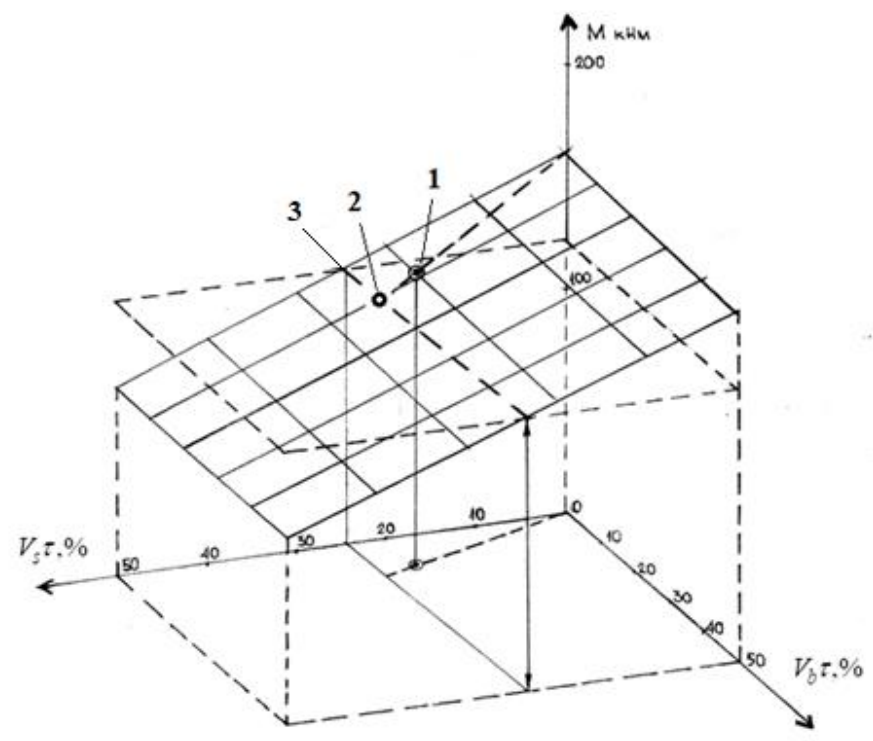

Fig. 4. Bearing capacity of the beam B-4 normal section depending on the concrete corrosive wear degree in the compressed zone and tensile reinforcement: 1 - the position of the individual structure at the examination time; 2 - point corresponding to the onset of the I group of limit states, 3 - border of the unacceptable moments area.

Calculation diagram of the beam B-4 in accordance with the existing practice can be taken in the form (Fig. 5):

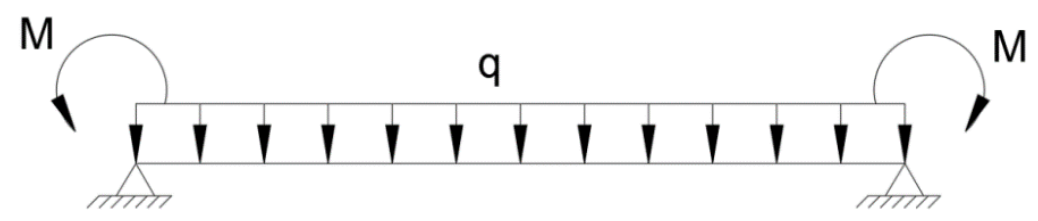

Fig. 5. Design scheme of the beam B-4, where $q=49.4 \mathrm{kN} / \mathrm{m}, M_{\max }=123.0 \mathrm{kN} \cdot \mathrm{m}$. 
Next, we solve the system of equations (7) and find $\tau_{3}=24$ of the year. The average residual life of the structure under study will be $T=24-20=4$ of the year. In this case, the residual resource availability is $P(\mathrm{t})=0.9$.

\section{Conclusions}

1. The results of the chemical industry objects' load-bearing structures mass survey show that the dominant factor determining their durability is the corrosive wear of the stretched reinforcement and the concrete compressed zone. At the same time, as a rule, there are no external signs of the onset of the limiting states of group II. However, at the same time, there is a significant corrosive wear of the longitudinal and transverse reinforcement cross-sectional area, damage to the protective concrete layer, a decrease in the cross-sectional area of the concrete compressed zone.

2. Under operating conditions, the structure stress-strain state level is a factor that controls the rate and nature of concrete and reinforcement corrosive wear degradation processes. In this case, uneven corrosive wear leads to a sharp increase in the inhomogeneity of the sections' stress-strain state. This circumstance predetermines the possibility for the limiting state onset of the I group in the local zone in the II group limiting states failures' onset external signs absence.

Thus, for these structures, an indispensable condition is an assessment of the residual life according to safety conditions.

\section{References}

1. V.V. Petrov, I.G. Ovchinnikov, Yu.M. Shikhov, Calculation of structural elements interacting with an aggressive environment (Publishing House of the Saratov University, 1987)

2. L.M. Pukhonto, Engineering reinforced concrete structures durability (silos, bunkers, reservoirs, water towers, retaining walls) (Publishing House ASV, M., 2004)

3. Geuntae Hong, Byung-Uk Na, Seongcheol Choi, Rebar corrosion of a continuously reinforced concrete pavement being used for more than 30 years on the Jungbu Expressway (Construction and Building Materials, Korea, Vol. 277, 2021).

4. Sheetal Sahare, Bilavari Karkare, Case Studies in Construction Materials 13, (2020)

5. Yarong Song, Elaine Wightman, Jagadeeshkumar Kulandaivelu, Hao Bu, Zhiyao Wang, Zhiguo Yuan, Guangming Jiang, Water Research 182, (2020)

6. M. Oki, S.A. Akintola, A.A. Adediran, P.P. Ikubanni and B.T. Ogunsemi, Journal of Physics: Conference Series 1378, (2019)

7. Bowen Zheng, IOP Conference Series: Earth and Environmental Science 300, 2019.

8. Yu Zhang, Jun Ge Huang and Jing Shu Liu, IOP Conference Series: Earth and Environmental Science 719, (2021)

9. V Naveen Kumar, J Daniel Ronald Joseph, M Ashok and MP Suresh, IOP Conference Series: Materials Science and Engineering 989, (2020)

10. J. Hackl, J. Kohler, Structural Safety 62, 12-23 (2016) 
12. D.I. Korolkov, A.G. Chernykh, T.N. Kazakevich, S.M. Mamedov and M.V. Gravit, IOP Conference Series: Materials Science and Engineering 775, (2020)

13. Mingyang Zhang, Naoki Nishiya, Mitsuyoshi Akiyama, Sopokhem Lim, Keisuke Masuda, Construction and Building Materials 264, (2020)

14. Jaya Nepal and Hua-Peng Chen, Journal of Physics: Conference Series 628, (2015)

15. A.N. Dobromyslov, Assessment of the buildings and structures reliability by the external signs. Reference manual (Publishing House ASV, M., 2004) 